\title{
Apuntes etnográficos sobre lo digital y la lengua en Maré, Río de Janeiro
}

\author{
MARIA PILAR CABANZO \\ Universidade Federal Fluminense, Niterói, Rio de Janeiro, Brasil \\ pilarcabanzo@gmail.com \\ DANIELLY RODRIGUES \\ Pesquisadora Independente, Rio de Janeiro, Rio de Janeiro, Brasil \\ daniellyrodriguesrj@gmail.com
}

DOI 10.11606/issn.2316-9133.v29i2pe175263

resumen Este artículo presenta un abordaje etnográfico de las interacciones en un grupo de Whatsapp de un curso de Español en la favela de Maré, Rio de Janeiro. Tales interacciones son asumidas metodológicamente como rastros o marcas visuales de identificación y presentación de sí mismos de los integrantes del grupo. Al analizar las interacciones, se resalta la centralidad de la lengua en la reproducción de relaciones de dominación. Entre los mensajes intercambiados, se da especial destaque a aquellos concernientes a la elaboración conjunta de un diccionario Portugués/Español. Las reflexiones suscitadas en el grupo a partir de las acepciones recogidas revelan interrogantes sobre la supuesta neutralidad de la lengua, tan presente en contextos de aprendizaje de idiomas. Se destaca la fluidez de las prácticas lingüísticas - que van más allá de las dicotomías oral / escrito / offline / online - y su estrecha relación con un espacio habitualmente vinculado a la falta, a la pobreza y a la violencia. En ese sentido, este artículo reflexiona sobre las condiciones de acceso y usos de Internet en Maré a partir de un estudio de caso, proponiendo articulaciones entre trabajo antropológico, usos de la lengua y ambientes digitales.

palabras clave Español. Whatsapp. Maré. Internet. Etnografía.

\section{Notas etnográficas sobre o digital e a língua na Maré, Rio de Janeiro}

resumo Este artigo apresenta uma abordagem etnográfica das interações em um grupo de Whatsapp de um curso de Espanhol realizado na favela da Maré, no Rio de Janeiro. Essas interações são assumidas metodologicamente como rastros ou marcas visuais de 
identificação e apresentação de si dos integrantes do grupo. Ao analisar as interações, destaca-se a centralidade da língua na reprodução de relações de dominação. São descritas as mensagens trocadas, dando especial atenção à elaboração conjunta de um dicionário Português/Espanhol. As reflexões suscitadas no grupo a partir dos verbetes coletados revelam interrogantes sobre a suposta neutralidade da língua tão presente em contextos de aprendizado de idiomas. Destaca-se a fluidez das práticas linguísticas - que vão além das dicotomias oral/escrito e off-line/online - e sua estreita relação com um espaço habitualmente associado à falta, pobreza e violência. Nesse sentido, o artigo reflete sobre as condições de acesso e usos de Internet na Maré a partir de um estudo de caso, propondo articulações entre trabalho antropológico, usos da língua e ambientes digitais.

palavras-chave Espanhol. Whatsapp. Maré. Internet. Etnografia.

\section{Ethnographic notes on digital and language in Maré, Rio de Janeiro}

abstract This article presents an ethnographic approach to the interactions in a Whatsapp group of a Spanish course in the favela of Maré, in Rio de Janeiro. Methodologically, these interactions are assumed as traces or visual marks of identification and presentation of self of the group members. When analyzing the interactions, we highlight the significance of the language in reproduction of domination relations. We describe the posts, especially those related to collective construction of a PortugueseSpanish dictionary. The discussions in the group that emerged from the entries collected reveal questions about the supposed neutrality of the language in learning contexts. We remark the flow of the language practices beyond the oral/written and offline/online dichotomies. We also emphasize the close relations between those practices and a space usually associated with absence, poverty and violence. The article thus discuss the conditions of access and uses of the Internet in Mare from a case study. Therefore, we propose articulations between anthropological work, language uses and digital environments.

keywords Spanish. Whatsapp. Maré. Internet. Ethnography.

\section{Introducción}

Este artículo propone un abordaje etnográfico de las interacciones de un grupo de Whatsapp integrado por participantes de un curso de español realizado en las instalaciones de una organización civil en la favela de Maré, Rio de Janeiro. Frente a la imposibilidad de continuación de las clases debido a la proliferación del coronavirus, la interacción entre los participantes del curso pasó a ser exclusivamente por la famosa aplicación de mensajería instantánea. Las autoras del artículo, transitando entre los papeles de investigadoras y profesoras del curso, analizamos las interacciones centrándonos en aquellas referentes a la elaboración conjunta de un diccionario portugués-español. Discutimos las reflexiones de los participantes del grupo acerca del carácter posicionado de la lengua y su relación con la favela. De este modo, proponemos articulaciones entre trabajo antropológico, usos de la 
lengua y ambientes digitales. Los objetos de pesquisa y análisis que aquí presentamos no están integrados a ninguna agenda de investigación ni hacen parte de proyectos más amplios de pesquisa.

Iniciamos con una discusión sobre el carácter de nuestro abordaje, destacando que los trabajos académicos sobre ambientes digitales y prácticas lingüísticas suelen centrarse en los aspectos formales de las segundas. Lo que proponemos aquí es una aproximación antropológica que transita entre varios contextos y busca identificar los efectos de tales tránsitos en las interacciones analizadas. Proseguimos apuntando el estrecho vínculo entre la lengua y las relaciones de dominación para comenzar a presentar las interacciones en el grupo de Whatsapp. Posteriormente, nos enfocamos en la elaboración conjunta del diccionario, a partir de una discusión sobre las condiciones de acceso a Internet en la favela. Finalizamos evidenciando la naturaleza performativa de las interacciones del grupo de Whatsapp. Aunque el diccionario surge de un vínculo estrecho con la cotidianidad de la favela, no se limita a esta. En contraste, las interacciones en el grupo de Whatsapp parecen ir en sentido opuesto: estas son valoradas en sí mismas y por el compromiso con el estudio del español que representan. Temas y cuestiones considerados ajenos y potencialmente conflictivos son rápidamente descartados.

\section{Un comentario sobre método}

Los trabajos académicos que abordan las relaciones entre usos lingüísticos y aplicaciones de mensajería instantánea usualmente se enfocan en contextos de escolarización formal para resaltar elementos formales de la lengua (MASTRELLA-DE-ANDRADE 2020) o contribuyen con el debate sobre populismos contemporáneos (SILVA 2020; RODRIGUES; FERREIRA 2020). Aquí proponemos un abordaje antropológico que, aunque se concentra en las interacciones en un grupo de Whatsapp, las atraviesa y rebasa, comenzando por interpelar los rastros de las presencias reunidas alrededor de tal grupo.

Al pensar sobre sus investigaciones en ambientes digitales, Gomes y Leitão (2011) sugieren la fragmentación y desestabilidad de la presencia humana como eje definitivo de tales ambientes. Mentes y cuerpos, antes unidos biológicamente, ahora estarían fundidos en máquinas y tecnologías a su vez imprescindibles para la interacción (GOMES; LEITÃO 2011). Las relaciones se realizarían en las máquinas y a través de estas, valiéndose de los cuerpos humanos pero rompiendo presencias hasta entonces establecidas ${ }^{1}$.

La exigencia de ciertos instrumentos y elementos como requisito de identificación y principio de relación está presente en diferentes dimensiones de realidad, online u offline. Por ejemplo, Peirano (2014) recuerda en ciertos ambientes la información contenida en los

\footnotetext{
${ }^{1}$ Latour (2016) y Segata (2016) proponen avances sobre esta cuestión, pensando los vínculos como asociaciones entre naturalezas potencialmente distintas. De esta manera, los programas de computador, las llamadas plataformas, los propios equipos no son escenarios de la acción humana, sino partes integrantes de una cadena de asociaciones con variados efectos recíprocos.
} 
llamados documentos personales o de identificación ${ }^{2}$ - objetos externos a nuestro cuerpo es el único medio que confirmará nuestra condición y posibilitará cualquier relación. Basta pensar en los trámites necesarios para competir por una vacante de empleo o para solicitar una ayuda del gobierno. En otros ambientes, prosigue Peirano (2014), la identificación será realizada a partir del contexto o por el uso de los sentidos. El "nombre" - en muchas ocasiones diferente de aquello que aparece en los documentos personales - nuestro rostro, nuestra voz, serán suficientes para reconocernos.

Partimos entonces de la existencia de rastros, marcas, mecanismos de identificación como máquinas y documentos, entrelazados de forma fragmentaria en ambientes online y offline, para comenzar a describir el grupo de Whatsapp conformado por alumnos y profesores de un curso de español ofrecido a los habitantes de Maré en las instalaciones de una organización civil reconocida en la favela. El grupo fue creado por una de las profesoras hace algunos años y actualmente cuenta con cerca de 100 integrantes.

Hasta la cancelación de las clases, la información que circulaba en el grupo se refería principalmente a las actividades realizadas en las clases. Los participantes también informaban sobre los tiroteos en Maré, lo que, además de ayudar a los habitantes a organizar su tránsito por la favela, determinaba la realización o cancelación de las clases, dependiendo de la intensidad y proximidad de la confrontación. Por lo tanto, al menos dos acontecimientos offline, a saber, las clases presenciales o la expectativa de su realización y la inminencia de tiroteos, constituían la base de interacción de los participantes. Todos los participantes están habilitados para enviar mensajes al grupo, administrado por cuatro profesoras. Algunos de los participantes acudieron al curso durante años - en la figura de profesor o alumno -, otros apenas se vieron en las contadas clases que ocurrieron en 2020. Así, lo que vincula a todos es alguna relación con el curso de español.

En el presente artículo, abordamos este grupo centrándonos en las interacciones entre los perfiles asociados a los participantes del grupo. De este modo, nuestro interés no recae en las relaciones a partir, por ejemplo, de la información alfanumérica de los documentos personales ni de la presencia y actitud de cuerpos físicos. En contraste, los vínculos que aquí nos interesa abordar suceden entre los variados rastros visuales que constituyen el perfil de cada participante. Así, por ejemplo, aquel que todos llaman Jonas en las clases y en el intercambio de mensajes, aparece también en el grupo como "Deus no comando", acompañado de diferentes emoticones. Entendemos tales marcas gráficas como elementos de identificación e imágenes o presentaciones de sí mismo, en el sentido atribuido por Goffman (1980), definidas por valores inteligibles para los participantes. Estas marcas también nos sirven como recurso de escritura del presente texto. A partir de un juego entre nombres y status de perfil, las autoras y los interlocutores de investigación citados a lo largo

\footnotetext{
${ }^{2}$ En este famoso software de intercambio instantáneo de mensajes por Internet es posible enviar mensajes a varias personas a la vez, mediante las llamadas listas de transmisión, en las cuales el usuario que crea la lista es el único que puede realizar envíos, y a través de los grupos, administrados por uno o varios usuarios, quienes pueden definir las condiciones de intercambio de mensajes entre los participantes.
} 
del texto son identificados con elementos diferentes a los que aparecen en sus documentos personales.

Por último, abordar etnográficamente un grupo de Whatsapp radicaliza las inquietudes, tan presentes en el trabajo antropológico articulado a contextos urbanos, sobre el comienzo y fin del trabajo de campo. Antes de presentarse como investigadoras, las autoras tienen relación con el grupo porque son profesoras del curso. Así, el grupo es uno de los tantos en los cuales las autoras participan cotidianamente. Con las restricciones de circulación debido a la proliferación del coronavirus, las actividades relacionadas con este artículo fueron realizadas en Internet. Además de intercambiar mensajes en el grupo con alguna frecuencia, las autoras discutieron la confección del texto mediante una plataforma online de reuniones, conversaron con el resto del profesorado en otra plataforma, consultaron textos y construyeron la escritura en un procesador de texto en línea.

Si asumimos que la escritura también hace parte del trabajo de campo en la medida en que posibilita repensar las hipótesis y análisis en curso (BECKER 2015), entonces podemos decir que el abordaje etnográfico no termina ni comienza en el grupo de Whatsapp - es decir, este no es una entidad autónoma y aislada. Nuestro trabajo de campo abarca relaciones entre el grupo y otras situaciones online y offline. Estamos de acuerdo entonces con Miller y Slater (2000) cuando sugieren que el abordaje etnográfico permite identificar las atribuciones recíprocas de sentido entre varias dimensiones. De este modo, analizar el grupo de Whatsapp de un curso de español realizado en Maré, Rio de Janeiro, nos lleva a considerar los múltiples vínculos entre prácticas lingüísticas, Internet y espacios urbanos, como sugerimos en las siguientes secciones.

\section{La lengua y las relaciones de dominación}

Una de las reglas del grupo, de vez en cuando enfatizada por alguna de las profesoras, es que los mensajes intercambiados sean en español. Eventuales mensajes en portugués, como ofertas de vacantes de empleo o, en tiempos de coronavirus, anuncios de donación de alcohol en gel y cestas de alimentos, suelen ser publicados precedidos por un mensaje del autor justificando la presencia del portugués. Mensajes cuya sintaxis difiere de la norma de la lengua escrita solamente serán comentados si el autor o la autora así lo solicitan. En algunas ocasiones, los propios autores perciben las divergencias y escriben un nuevo mensaje siguiendo la norma. El portugués también aparece en palabras o expresiones cortas como reacción a las conversaciones que se desarrollan. Los mensajes suelen estar acompañados de emoticones. La escritura prima sobre las llamadas notas de voz.

Consideramos que este uso fluido de la escritura - intercalando diversos elementos gráficos, que incluyen emoticones, abreviaciones y repeticiones en portugués y español - es una interpelación a la predominancia de la norma de la lengua escrita. Esta norma es usualmente entendida como adecuada y correcta, pues se aplicaría a la variedad de contextos y situaciones que demandan comunicación escrita. Así, un correo electrónico, un artículo científico, una historia y una opinión en las llamadas redes sociales digitales serían 
equiparables en términos de la exigencia de cumplimiento de aquella norma. Y aunque en las interacciones en esas redes eventuales desvíos de la norma suelen ser más tolerados, no faltan las numerosas quejas sobre las supuestas distorsiones lingüísticas en Internet. Estas serían, a su vez, síntoma de las pocas habilidades lectoras de las nuevas generaciones. Los ambientes digitales aparecen entonces como campos de reproducción y disputa de las relaciones de poder por detrás de las prácticas lingüísticas.

Varios autores nos recuerdan el carácter posicionado de la lengua. Al analizar las consecuencias de la colonización, Fanon (2008) destaca el dominio del lenguaje como promesa de reconocimiento y herramienta de subordinación. El autor analiza el comportamiento de los habitantes negros de las antiguas colonias francesas en las Antillas. Aquellos que demostraran mayor competencia de la lengua francesa, estarían más cerca de los valores civilizatorios y metropolitanos, negando, por lo tanto, la relación de dominación - y la diferencia de color que implica - en la cual se encuentran (FANON 2008). Para Bourdieu (1983), la lengua es un elemento de dominación. Los sistemas educacionales adoptan una variedad lingüística específica, lo que acaba favoreciendo su progresiva hegemonía sobre otras, pasando a predominar inclusive en nuevos ámbitos. Para acceder a ciertas posiciones o ingresar a determinados campos será indispensable demostrar competencia en la variedad exigida (BOURDIEU 2007). En ese sentido, el dominio de ciertas variantes tiene que ver tanto con la propia historia del desarrollo de la lengua como con la distribución del poder que impide o permite la reproducción de tales variantes.

Así por ejemplo en el curso de español a partir del cual se originó el grupo de Whatsapp los temas abordados siguen la secuencia y directrices de enseñanza del Marco Común de Referencia Europeo. Al finalizar cada semestre, los alumnos deben realizar una evaluación, inspirada en la misma normativa, como requisito para ser admitidos en el siguiente nivel del curso. El curso también ofrece becas para realizar sin ningún costo los exámenes necesarios para obtener una certificación oficial, emitida por una reconocida institución española que participa en la elaboración de la normativa. Esto atrae a muchos de los alumnos del curso, especialmente aquellos interesados en vacantes de empleo que exigen el dominio de un segundo idioma. Otros alumnos están en la universidad y acuden al curso como parte de su formación. Hay jubilados y amas de casa - algunas de ellas van al curso con sus hijos pequeños. De este modo se reproduce, se difunde y se establece la variante determinada por el Marco Común de Referencia Europeo y llamada por todos los involucrados en el curso - desde alumnos y profesores hasta el organismo que elabora la normativa - como español.

La idea de que este español es una variante es brevemente discutida en las primeras clases de cada semestre, cuando se presenta el programa del curso. Alumnos y profesores comentan la existencia de lenguas indígenas, usualmente camufladas en las llamadas lenguas oficiales, o debaten, por ejemplo, cuáles serían los saludos más comunes entre los habitantes de Maré y que tal vez no fuesen tan frecuentes en otros lugares o con gente que no conoce la favela. Pero solo a partir de la recomendación de aislamiento los participantes del curso 
comenzaron a abordar con ahínco probables articulaciones entre la lengua y el espacio habitado, como describimos a continuación.

\section{Maré e Internet}

Maré se localiza entre la Avenida Brasil y la Linha Vermelha, dos importantes vías de comunicación de la ciudad de Río de Janeiro con el resto del país y cuenta con alrededor de 130 mil habitantes (IBGE 2010). Como tantas otras favelas, Maré se caracteriza por la construcción auto gestionada y la movilización colectiva, en un contexto histórico de variable intervención estatal. En la década de 1940, la región, hasta entonces un extenso manglar con pocas áreas secas ocupadas por pescadores, experimentó definitivas transformaciones urbanísticas. El ensanchamiento de la Avenida Brasil y la construcción de la Ciudad Universitaria, campus perteneciente a la Universidad Federal de Río de Janeiro, atrajeron un contingente significativo de trabajadores de la construcción civil, muchos de los cuales terminaron por establecerse en la región (REDES 2012).

Algunas décadas después, durante la dictadura militar y como parte de proyectos de urbanización, fueron construidos conjuntos residenciales en algunas áreas de Maré, la cual hasta hoy cuenta con diferentes modalidades de vivienda, entre barracas de madera y casas y apartamentos de ladrillo. Maré fue reconocida oficialmente como conjunto de barrios y área administrativa en 1988, a través del decreto 7980 (RIO DE JANEIRO 1988). Esto no disminuyó la histórica estigmatización del conjunto de favelas, debido no solo a las condiciones precarias de vivienda y servicios públicos sino también a la manifiesta presencia de diferentes grupos dedicados al tráfico de drogas. La violencia, derivada de los constantes conflictos entre tales grupos y contra la policía, cuya presencia redunda en continuos abusos sobre los habitantes, hace parte del día a día de quienes circulan por la favela. Así mismo, la violencia es el principal, si no el único tema de los grandes medios de comunicación en las poquísimas ocasiones en que Maré es mencionada ${ }^{3}$.

Maré también se caracteriza por una intensa movilización de organizaciones civiles, las cuales están presentes desde la década de 1990 y son las responsables de la mayor parte de la variada oferta gratuita de educación no formal de la favela. Tales entidades también atraen a numerosos extranjeros, los cuales suelen relacionarse con la intensa agenda de actividades de esas entidades bajo las figuras de investigadores becarios, funcionarios y voluntarios encargados de diversas tareas ${ }^{4}$.

\footnotetext{
${ }^{3}$ Por ejemplo, mientras escribíamos el presente artículo, un reportaje de uno de los principales periódicos de Río de Janeiro presentó Maré como “búnker de bandidos”, lo que generó una oleada de comentarios indignados en plataformas digitales. Algunas horas después, el titular fue modificado y apenas se resaltó el número de fugitivos de la justicia - 244 - que supuestamente se esconde en la favela (RIANELLI et al. 2020). Temas ajenos a la violencia, como por ejemplo las numerosas actividades de información, prevención y ayuda relacionadas con la expansión del coronavirus, llevadas a cabo por los habitantes de Maré, brillan por su ausencia en los reportajes de los grandes medios de comunicación brasileños.

4 Según el censo realizado na favela en 2013, 0,2\% de los habitantes fueron identificados como extranjeros (REDES... 2019).
} 
Una de las autoras de este artículo, a quien a partir de ahora llamaremos Celine, llegó a Maré en este contexto, dando clases en un curso nocturno de preparación para la admisión en la universidad ofrecido por una reconocida organización civil de la favela. Celine fue profesora allí durante dos años, marcados por el ingreso y la presencia permanente del ejército federal en la favela, lo que vino a sumarse a la serie de factores que determinan el día a día en Maré. Por ejemplo, se volvió costumbre tener que someterse a la requisa por parte de los soldados al final de la tarde, cuando oleadas de personas entran y salen de la favela en virtud de sus múltiples obligaciones diarias. Las frecuentes requisas, además de generar indignación por los habituales abusos cometidos durante estas, también acababan por atrasar el inicio de las clases.

La otra autora de este artículo, a quien en adelante denominaremos Rita, es habitante de Maré. Rita fue alumna de Celine durante algunos meses, al cabo de los cuales abandonó el curso nocturno de preparación para la admisión en la universidad para concentrarse especialmente en el estudio del español. Unos años después, Rita ingresó al curso de español ofrecido por las mañanas en las instalaciones de la misma organización y pasó a ejercer tareas de monitoría, vinculándose poco a poco como la única profesora brasileña e invitando a Celine a incorporarse al profesorado. Vale resaltar que la organización civil que ofrece su espacio para las clases también suministra las fotocopias de material distribuido a lo largo del curso. Finalmente, esta organización no posee ninguna relación contractual con el profesorado, el cual tiene autonomía para definir los aspectos pedagógicos y curriculares del curso.

En marzo de 2020, unas semanas después del inicio del curso, las clases fueron canceladas en función de la recomendación de aislamiento. Los dos meses siguientes, en el grupo de Whatsapp comenzaron a abundar preguntas sobre las posibilidades de retorno de las clases presenciales. Era cada vez más evidente que cualquier intento de continuidad del curso exclusivamente mediante plataformas digitales tendría escaso alcance, pues el acceso a Internet en Maré está rodeado de dificultades.

Como en otros ámbitos de la vida en esta favela, las escasas e irregulares políticas públicas se relacionan con las condiciones de uso de las llamadas tecnologías de información y comunicación. A comienzos de 2003 fueron instaladas dos antenas, en el marco de un convenio de la Universidad Federal de Río de Janeiro con una institución canadiense. Según Silva de Lima y Cukierman (2011), el objetivo de esta iniciativa era integrar Maré a la red de computadores formada por las principales instituciones de investigación de Río de Janeiro, posibilitando el acceso gratuito a Internet en las escuelas públicas de la favela. Para los autores, la progresiva proliferación de las llamados lan houses y la hegemonía de una única empresa de telecomunicaciones habrían favorecido la desactivación de las antenas, ocurrida pocos años después (SILVA DE LIMA; CUKIERMAN 2011). Hasta el día de hoy, tal empresa es la única disponible en Maré, lo que, para Rita, acaba derivando en servicios de calidad irregular, pues, al no tener competencia, tal empresa, además de especular con las tarifas de prestación de servicios, no estaría interesada en invertir en la manutención de equipos. 
Iniciativas de acceso comandadas por universidades públicas y por la alcaldía fueron realizadas hasta, por lo menos, 2014 (PREFEITURA 2009; DAVID 2014) y siempre desde la perspectiva de la falta ${ }^{5}$. Con la subsecuente proliferación de los smartphones ${ }^{6}$, que condensan en un único aparato variadas funciones antes separadas en varios, desplazarse hasta un lugar para entrar a Internet dejó de tener sentido para muchos de los habitantes. La vida en la favela pasó a construirse en alguna medida a través de la ubicuidad de Internet. En la favela, los smartphones son tanto de uso colectivo y doméstico - un aparato permanece en casa y es usado por sus integrantes - como de carácter individual y personal, con cada integrante contando con uno o varios aparatos apenas para sí mismo. Hacia 2018, el 36,7\% de los domicilios en Maré afirmaban contar con acceso doméstico a Internet (REDES 2019).

Con la recomendación de aislamiento y las clases canceladas, comenzaron a aparecer en el grupo de Whatsapp del curso mensajes sobre prevención del coronavirus e información sobre puntos de donación de cestas de alimentos. Algunos participantes se pusieron a disposición para ayudar a quien así lo necesitara en la preparación de los exámenes de admisión a la universidad, otros publicaron mensajes sobre vacantes de empleo. La profesora Moema, que trabaja en la organización que proporciona los certificados oficiales de suficiencia en español, pasó a publicar la agenda de actividades online de la organización, especialmente películas y reportajes cortos. Imágenes sobre vocabulario o temas específicos del estudio del español continuaron siendo publicadas y comentadas. También persistió la información sobre los tiroteos y las operaciones de la policía, que nunca se detuvieron, ajenos a la proliferación del coronavirus (AQUINO 2020; O GLOBO 2020). En agosto fueron integrados al grupo algunos compañeros de trabajo de Jane, una alumna que integra un proyecto de investigación sobre el medio ambiente y la cotidianidad llevado a cabo por varias organizaciones civiles extranjeras. Jane y sus compañeros publicaron en el grupo videos y textos cortos sobre su experiencia cotidiana con el medio ambiente, recibiendo elogios de alumnos y profesores.

Además, en el grupo también estuvo presente la confusa mezcla de teorías de conspiración, fórmulas, remedios y oraciones tan presente en las interacciones en Whatsapp. Durante las primeras semanas de la recomendación de aislamiento, comenzaron a aparecer mensajes sobre "curas espirituales" para combatir la covid-19. Algunos alumnos y profesores reaccionaron comentando que esta información era falsa o resaltando que el objetivo del grupo era compartir datos provenientes de fuentes "oficiales"7 y en Español.

\footnotetext{
${ }^{5}$ Por ejemplo, el programa Internet Itinerante llevado a cabo por la alcaldía pretendía alcanzar áreas consideradas como "desiertos digitales" (PREFEITURA 2009).

6 En 2018, 95\% de los brasileños afirmaba tener teléfono fijo o móvil en casa, mientras que $98 \%$ de los entrevistados alegaba usar smartphone para entrar a Internet (IBGE 2018).

7 "oficial” aquí tiene un doble sentido: es una citación - algún participante del grupo efectivamente usó esta palabra para referirse a fuentes que serían verídicas - y también remete a la ironía. Como es sabido, el actual gobierno brasileño se ha caracterizado por usar los canales oficiales de información para difundir noticias falsas.
} 
Estrella Fugaz, quien reproducía estos mensajes, usualmente respondía con emoticones de corazón.

En una ocasión los mensajes de Estrella Fugaz ocasionaron algo más que un llamado de atención seguido de corazones. Frente a una columna de opinión aparecida en un reconocido periódico brasileño y reproducida por Estrella Fugaz, Sin Preocupaciones quiso saber qué parte Estrella Fugaz no había entendido acerca del español como idioma privilegiado en el grupo. Por su parte, La Vida es Bella preguntó si había algún modo de impedir que Estrella Fugaz enviara mensajes. Irene pidió calma y agregó: "Pero la calma se mantiene con las reglas, vamos a cumplirlas para evitar polémicas en el grupo". Desde entonces, Estrella Fugaz no volvió a publicar mensajes en el grupo.

Así, el intercambio de mensajes en el grupo cristaliza la idea del acceso a Internet como promesa del mundo, si bien en un sentido bastante diferente al optimismo característico de las primeras reflexiones sobre la expansión digital en la década de 1990 (LÉVI 1999). Estar en Internet parece ser requisito ineludible para estar en el mundo - para conseguir empleo, para definir rutas de acuerdo a los tiroteos, para expresar y difundir creencias. El lenguaje, la vida, el trabajo se producen en y a través de las máquinas (HARAWAY 2009).

La propuesta inicial del profesorado para intentar dar alguna continuidad del curso de español fue mantener el día y horario de las clases presenciales para encuentros y realización de tareas en el grupo de Whatsapp. El profesorado propuso cuatro actividades. La primera se trataba de contar, en español y en formato audiovisual, cómo estaba la vida durante las primeras semanas del aislamiento. Las grabaciones serían publicadas en el canal YouTube del curso. Nina dio algunas recomendaciones para prevenirse del coronavirus, Moema se transformó en Jacinto, un personaje ficticio. Irene adicionó tiras coloridas y llamativas a su grabación. La Vida es Bella declamó una de sus poesías. Vivir con Alegría publicó fotos de las reformas que hizo en las macetas de sus plantas.

La segunda actividad consistía en revisar temas ya vistos. Otra de las actividades propuestas era realizar pequeñas investigaciones - usando material disponible en casa, preguntando a familiares, vecinos, compañeros de trabajo - sobre una serie de temas propuestos por el profesorado y escribir un texto corto sobre el tema, el cual sería debatido en el periodo anteriormente dedicado a las clases presenciales.

Estas actividades tuvieron poco eco. En una de las pocas sesiones que ocurrieron, Luz de Luna avisó que tal vez se ausentaría durante algunos minutos para atender a su pequeño hijo. Con las escuelas cerradas debido a la recomendación de aislamiento, el chico permanecía en casa todo el día demandando mayor atención materna. Quedarse en casa no era posible para muchos otros alumnos, cuyos horarios y lugares de trabajo cambiaron, dificultando su participación en el periodo previsto para el estudio de español. Para algunos, las dificultades eran "técnicas". La alumna Merci afirmaba asistir a las sesiones en la casa de una amiga, donde Internet funcionaba mejor. Si la amiga tuviera que salir o realizar alguna tarea ruidosa, la participación de Merci estaba comprometida. 
Finalmente, una actividad posibilitó alguna continuidad del curso, tal vez debido a la ausencia del imperativo de acceder a Whatsapp en horarios específicos. La propuesta fue la siguiente: cada alumno enviaría por lo menos diez palabras y expresiones comunes en su barrio con la descripción de su significado en español, elaborada por el propio alumno. El envío podría ser realizado directamente al grupo o por mensaje particular a cualquier profesora, mediante Whatsapp o correo electrónico. Una vez recopiladas al menos 50 palabras con sus definiciones, el profesorado propondría posibles correspondencias en la variedad de español que le fuera común. Rita dibujaría algunas definiciones y correspondencias. El resultado de este proceso sería en formato digital y tal vez impreso.

$\mathrm{Al}$ cabo de unos tres meses, el alumnado había enviado alrededor de trescientas palabras, siempre por mensaje particular a alguna de las profesoras. Con tal cantidad de acepciones, un número mucho mayor que el inicialmente esperado, el profesorado optó por concluir la fase de recogida y comenzar la búsqueda de probables correspondientes en las variaciones del español que le son familiares. De este modo, las correspondencias también estarán vinculadas a los diferentes usos y situaciones de interacción de las profesoras. Como esta fase está en curso, no la incluimos en el presente texto.

Muchos de los envíos consistieron en listas de términos con sus definiciones correspondientes, en archivos creados en procesadores de texto, en forma de presentaciones o en fotos de pedazos de papel con las acepciones escritas a mano. Para Josimar fue fundamental seguir algunas convenciones de los tradicionales diccionarios: "Tá na Disney. (expr. Coloq.) = Soñar despierto(a). "Meter o pé" ou "Ralar peito". (expr. Coloq.) = Salir, irse". Willis optó por utilizar sinónimos en las definiciones que propuso: "Formou - solía mostrar que estás de acuerdo con algo. Es sinónimo de "combinado". Meter o pé - significa que te vas del lugar. Es sinónimo de la jerga "vazar" o "cair fora”. Mary prefirió usar el modo imperativo para una de las acepciones que envió: "Marcar um dez": quédese un poco más en algún lugar, espere un poco mirando para entretenerse o molestarse con algo".

De esta manera, lo que el profesorado propone construir junto al alumnado difiere de las percepciones habituales asociadas a los diccionarios. Por una parte, son consideradas variedades del portugués y del español, enfatizando de este modo las interacciones lingüísticas cotidianas en detrimento de las concisas definiciones de los diccionarios de idiomas. En ese sentido, el diccionario va más allá del reconocimiento de la existencia de variedades lingüísticas y de las diferencias de situaciones de interacción, marcadas por clase, género, sexualidad o color de piel. Al mezclar formatos, modelos y códigos, el diccionario resalta la heterogeneidad de las prácticas lingüísticas cotidianas, interpelando la dicotomía oral / escrito a partir de la cual se suelen imaginar, elaborar y narrar las lenguas. Las diversas versiones escritas de términos usados en el día a día proponen tomar distancia tanto de asociaciones comunes a la dimensión oral - atrapada en el pasado, reflejo de los orígenes, manifestación popular - como de acepciones vinculadas a lo escrito - conocimiento científico y restringido, camino hacia el futuro. Así, seguimos a Lopes et al. (2017) y Silva y Lopes (2019), quienes recuerdan que tales dicotomías son producto de la modernidad y 
utilizadas para organizar las relaciones de poder e ideología, si bien aparecen cubiertas por un manto de neutralidad e autonomía en el ámbito escolar.

Por otra parte, el diccionario propuesto no estaría organizado por orden alfabético sino por categorías determinadas por marcas comunes entre sus elementos. Tales criterios surgieron a partir de las acepciones enviadas. El profesorado propuso diferentes clasificaciones que fueron transformándose de acuerdo a los comentarios del alumnado en el grupo de Whatsapp. Por ejemplo, varias acepciones están asociadas a momentos de comida y bebida en lugares públicos. En esta categoría, llamada "El menú del día o de la noche...Bora papar!", encontramos "água de bandido", descrita mediante las instrucciones de preparación de este coctel. También encontramos "podrão". Moema comentó que comía mucho "podrão" cuando recién llegó a Río y no tenía trabajo. Ella comía un churrasco por cinco reales. Luz de Luna comenta que "podrão" no es exactamente un churrasco, sino "pan de hamburguer, la carne, el queso, patata delgadita jejee, bacon y sauce”. Ella solía comerlo en la plaza del Parque União, uno de los barrios de Maré y que está rodeada de variados bares y restaurantes. Moema entonces agregó que, siguiendo la acepción de Luz de Luna, nunca había comido "podrão", "solo un perrito caliente por 1 real que venden en la calle Voluntários da Pátria [avenida del barrio Botafogo, localizado en la llamada área noble de la ciudad]".

Estos comentarios fueron seguidos por numerosos mensajes sobre la nostalgia que suscitaba conversar sobre "podrão", pues su consumo remete a la vida antes de la recomendación de aislamiento: "Una vez comi un tan grande con dos carnes y bacon. Ya no podía comer y aún quedaba la mitad. Respiré profundamente y comi", "a mi hijo le acuerda su padre. no están juntos por la quarentena". La animada secuencia sobre la estrecha relación entre socialización y comida terminó poco después del comentario de Sin Preocupaciones: "En Venezuela los llaman asquerositos. Decimos que vamos a comer asquerositos en el trailer de la esquina".

Otro grupo de términos suscitó un breve debate en el grupo. Para Irene, aquella categoría no debería integrar el diccionario, debido al carácter ofensivo de varios de sus elementos. Como la profesora comentó en una reunión online del profesorado, "no queremos enseñarles a los gringos [turistas que podrían tener acceso al diccionario] aún más machismo que el que vivimos cotidianamente". La opinión de Celine y otras profesoras era diferente. Al evidenciar el carácter discriminatorio de ciertos términos podríamos insistir en la necesidad de reflexión sobre las relaciones de poder que emergían de las lenguas. Callar términos considerados problemáticos no impide su libre circulación ni provoca, como en un acto de magia, la desaparición de situaciones violentas y opresivas imbricadas a las palabras. Tales términos deberían conformar el diccionario agrupados bajo un rótulo que llamara la atención sobre la incomodidad que producen.

La categoría fue llamada entonces "palabrotas y algunas palabras que no habíamos querido incluir, mas ‘fodeu!”. Irene comentó en el grupo: “Tenemos las dos primeras palabras "detectadas" como lenguaje que podría ser machista pero ¿qué os parecen a vosotros? PERIGUETE Y BARANGA”. Según Sirenita, "[baranga] es una palabra machista, 
sí. Para referirse a las mujeres "feas", poco elegantes. Creo que la belleza es relativa y fugaz. Pero la belleza del corazón, nadie borra. Creo que la mujer sufre demasiado. Tanto con machismo como con malas palabras". Rita afirmó que nunca había escuchado que un hombre fuera llamado "baranga" y que generalmente esa palabra era usada por hombres para referirse a las mujeres. Por su parte, La Vida es Bella comentó: "No creo que sea una palabra machista, pues las mujeres llaman otras así también”. Luz de Luna rebatió: “Mujeres pueden reproducir machismo. Pienso que sí... pues no tenemos muchas palabras en feminino. Cuando es más que una persona que hablamos usamos ellOs. Mismo que sea un hombre y veinte mujeres. A su turno, La Vida es Bella comentó: Perdón, pensaba que solamente los hombres que hacen machismo". Esta frase fue acompañada con varios emoticones: rostro pensativo, rostro triste y el puño cerrado con el pulgar hacia arriba.

Luz de Luna respondió:

És como el prejuicio racial.... solemos decir que las personas negras reproducen el prejuicio racial.... porque lo prejuicio racial contra los negros no fue criado por las personas negras y si por las personas blancas incluso son las personas blancas que son favorecidas y privilegiadas con él. Así mismo es con el machismo. Nosotras reproducimos el machismo. Nosotras no le creamos y no somos privilegiadas ni favorecidas con él. Al contrario, todavía, mujeres son vitimas del machismo. (8 de Mayo de 2020)

A este mensaje, bastante más extenso que los intercambiados habitualmente en el grupo, le siguieron emoticones de aplausos por parte de varios participantes. Esto concluyó la discusión. No fue realizado ningún comentario sobre "periguete" y los términos incómodos no volvieron a ser abordados en el grupo.

Finalmente, el profesorado propuso en el grupo el ejercicio inverso: pensar términos a partir de categorías previamente establecidas. Se preguntó a los alumnos sobre expresiones que podría contener una categoría relativa a LGBTI. Irene puso una imagen con algunas palabras, diciendo que la recibió de un amigo, preguntando su significado y si sería adecuado incluir en el diccionario las acepciones que aparecen en la imagen. Santito definió "barbie" como "muchacho musculoso pero afeminado" y "bafo/basfond" como "fofoca increible". Para Willis "chuca" o, en sus palabras, "acto de limpiar el tracto intestinal generalmente con agua y una manguera de ducha para tener sexo anal", no debería ser incluida en el diccionario. Entre el continuo intercambio de mensajes sobre las definiciones, Rita y Willis llamaron la atención sobre el hecho de que ciertos términos son bienvenidos entre grupos de personas que se identifican con el paraguas LGBTI, pero pueden ser peyorativas cuando utilizadas por quienes no se denominan a sí mismos usando los elementos de tal sigla.

Vemos entonces que las interacciones en el grupo de Whatsapp no se reducen a meros intercambios de carácter gráfico. En contraste, estas se refieren a un tipo de 
experiencia que involucra los sentidos y evoca relaciones colectivas. Además de las múltiples referencias al consumo público de comida y bebida, el profesorado recibió numerosas acepciones asociadas a la evaluación de situaciones de interacción. Algunas de estas fueron "Fala sério: se usa cuando alguien te contó algo que no te gustó saberlo", "passa a visão": usamos para saber las "novidades" y "papo reto", con numerosas definiciones enviadas: conversación seria y sin engaño, transmitir una idea de manera objetiva, sin involucrarse, conversación totalmente sincera, sin mentiras ni tonterías. Tenemos aquí variados ejemplos de códigos verbales que proporcionan a los participantes de la interacción un abanico de posibilidades de acción que organizan y definen el contacto (GOFFMAN 1980). Así mismo, los signos publicados son performativos desde la perspectiva austiniana del lenguaje (AUSTIN 1990), es decir, tienen efectos, crean y modifican la realidad a partir de asociaciones con el espacio habitado, pero sin restringirse a este. En ese sentido, palabras, gestos y contexto producen el acto lingüístico (MALINOWSKI 1966).

Por eso, el diccionario no se organiza a partir de la hipótesis de que habría una lengua que sería propia o única de la favela. Aunque la propuesta del diccionario fue inicialmente presentada a los alumnos con el título "Diccionario favelés/mareense", las acepciones recogidas dan cuenta de fenómenos recurrentes en grandes ciudades y vividos especialmente por algunas generaciones. Así, "verdinha no es dinero y si marijuana" y "cara de lata es el carro de la policía". Si bien "favela" y "Maré" son puntos de partida y referencias fundamentales para reflexionar sobre las marcas de las prácticas lingüísticas, no se restringen a tales espacios. Las variadas acepciones evidencian los continuos tránsitos y adaptaciones lingüísticas de acuerdo a los contextos de interacción.

Finalmente, la intención de enfatizar la fluidez de las prácticas lingüísticas que pretende materializar el diccionario es un arma de doble filo. Por un lado, la recolección de acepciones implicó un pequeño ejercicio de investigación. Según algunos alumnos, fue necesario prestar especial atención en momentos que antes podían pasar casi desapercibidos: las historias de la madre o el esposo al volver del trabajo, las conversaciones entre las cajeras del supermercado, episodios vividos con compañeros de la escuela. Otros preguntaron directamente a amigos y familiares. Por otro lado, una vez concluido y distribuido, el diccionario podría apenas "divertir al gringo", como una de las profesoras afirmó en alguna reunión online del profesorado, acabando por reforzar estereotipos. Sería importante intentar controlar de algún modo la divulgación pública del diccionario con la intención de evitar que este acabe componiendo el menú de atracciones turísticas disponibles en la favela. Sin respuestas definitivas sobre cómo lidiar con esta posibilidad, solo resta aguardar la finalización del diccionario.

\section{Palabras finales}

Comenzamos con algunos apuntes sobre nuestro abordaje etnográfico, proponiendo un juego entre rastros o marcas de identificación como principio de interacción, tanto offline como online, y estrategia de presentación de las autoras y sus interlocutores de investigación. 
Además, resaltamos la agencia y los efectos recíprocos entre situaciones distintas, como señalado por Miller y Slater (2000). Proseguimos llamando la atención sobre la centralidad de la lengua para la reproducción de relaciones de dominación. Usualmente oculta, la prevalencia de la norma de la lengua escrita aparece como un fenómeno indiscutible, cuyo supuesto carácter neutro estaría ajeno a cuestiones de sexualidad, género, color de piel y clase. Proponemos que, aunque el curso de español es una instancia más de consagración lingüística, es posible analizar las interacciones en el grupo de Whatsapp asociado al curso desde la perspectiva de interpelación a ciertas normativas.

El tránsito fluido entre diferentes elementos gráficos que caracteriza la interacción en este grupo acabó desembocando en reflexiones sobre el espacio habitado y sobre el carácter inevitablemente posicionado de la lengua a partir de la propuesta de construcción conjunta de un diccionario portugués/español. La recomendación de aislamiento en función de la proliferación del coronavirus, imposible para muchos habitantes de Maré, trajo la posibilidad de reflexionar justamente sobre el hecho de vivir en la favela. Alumnos y profesores se vincularon mediante un pequeño ejercicio de investigación lingüística, generando interacciones y reflexiones sobre sus tránsitos online y offline. Por lo tanto, el particular diccionario que viene siendo construido puede ser interpretado como una subversión lingüística que, al recontar la propia historia (QUIJANO 1998), se opone a la supuesta falta con la que suele ser narrada la favela.

Finalmente, las interacciones en el grupo de Whatsapp tienen un carácter sociable desde la perspectiva simmeliana (SIMMEL 1983), privilegiando el propio momento de la interacción e intentando tomar distancia de asuntos que puedan causar conflictos. Vimos ejemplos de tal carácter al presentar las breves discusiones sobre acepciones potencialmente problemáticas y sobre las tensiones alrededor de la publicación de mensajes sobre tratamientos para la covid-19, considerados ajenos a los propósitos del grupo. Así, mientras el diccionario parece abrirse a la heterogeneidad de experiencias y de múltiples modos de estar en el mundo, el grupo de Whatsapp mira hacia adentro, procurando una inalcanzable armonía con base en la homogeneidad.

\section{Bibliografía}

AQUINO, Rai. (2020). Polícia faz megaoperação contra traficantes envolvidos em diversos roubos em Paracambi. O Dia, Rio de Janeiro, 13 mai. Disponível em: https://odia.ig.com.br/rio-de-janeiro/2020/05/5915407-policia-civil-realiza-

megaoperacao-contra-traficantes-envolvidos-em-roubos-em-paracambi.html\#foto=1.

Acesso em: 18 ago. 2020.

AUSTIN, John. (1990). Quando dizer é fazer. Tradução de Danilo Marcondes de Souza Filho. Porto Alegre: Artes Médicas.

BECKER, Howard S. (2015). Truques da escrita: para começar e terminar teses, livros e artigos. Tradução Denise Bottmann. Rio de Janeiro: Zahar.

BOURDIEU, Pierre. (1983). Sociologia. São Paulo: Ática. 
BOURDIEU, Pierre. (2007). A economia das trocas simbólicas. São Paulo: Perspectiva.

DAVID, Flávia. (2014). Prefeitura inicia programa Comunidade Limpa no Complexo da Maré. Rio de Janeiro, 26 jun. <http://www.rio.rj.gov.br/web/guest/ exibeconteudo?id=4789636>. Acesso em: 05.set. 2020.

FANON, Frantz. (2008). Pele negra, máscaras brancas. Salvador: Edufba.

GOFFMAN, Erving. (1980). A elaboração da face: uma análise dos elementos rituais na interação social. In: FIGUEIRA, Sérvulo. (Org). Psicanálise e Ciências Sociais. Rio de Janeiro: Francisco Alves, p.76-113.

HARAWAY, Donna. (2009). Manifesto ciborgue. Ciência, tecnologia e feminismosocialista no final do século XX. In: HARAWAY, D; KUNZRU, H; TADEU, T (Orgs.). Antropologia do ciborgue: as vertigens do pós-humano. Belo Horizonte: Autêntica Editora, p.33-120.

IBGE-INSTITUTO BRASILEIRO DE GEOGRAFIA E ESTATÍSTICA. (2010). Censo demográfico. Disponível em: <https://www.ibge.gov.br/estatisticas/sociais/ populacao/9662-censo-demografico-2010.html?=\&t=resultados $>$. Acesso em: 26.ago. 2020.

IBGE-INSTITUTO BRASILEIRO DE GEOGRAFIA E ESTATÍSTICA. (2018). Acesso à Internet e à televisão e posse de telefone móvel celular para uso pessoal 2018. Pnad contínua. Disponível em: <https://biblioteca.ibge.gov.br/visualizacao/livros/ liv101705_informativo.pdf>. Acesso em: 07.set. 2020.

LATOUR, Bruno. (2016). Faturas / Fracturas: da noção de rede à noção de vínculo. In: SEGATA, Jean; RIFIOTIS, Teophilos. (Orgs.). Políticas etnográficas no campo da cibercultura. Brasília: ABA Publicações; Joinville: Letra D’água, p.67-90.

LEITÃO, Débora Krischke; GOMES, Laura Graziela. (2011). Estar e não estar lá, eis a questão: pesquisa etnográfica no Second Life. Revista Cronos, Natal, v. 12, n. 2, p.23-38.

LÉVI. Pierre. (1999). Cibercultura. São Paulo: Editora 34.

LOPES, Adriana; SILVA, Daniel; FACINA, Adriana; CALAZANS, Raphael; TAVARES, Janaina. (2017). Desregulamentando dicotomias: transletramentos, sobrevivências, nascimentos. Trabalhos em linguística aplicada, Campinas, v. 56, n. 3, p. 753-780.

MALINOWSKI, Bronislaw. (1966). Coral gardens and their magic. A study of the methods of tilling the soil and of agricultural rites in the Trobriand Islands. London: George Allen \& Unwin Ltd., v. 1 e 2.

MASTRELLA-DE-ANDRADE, Mariana R. (2020). Abandonamos a sala da universidade: uma opção decolonial no estágio de inglês e na formação docente crítica. Revista Brasileira de Linguística Aplicada. Belo Horizonte, v.20, n.1, p.189-216

MILLER, Daniel; SLATER, Don. (2004). Etnografia on e off-line: cibercafés em Trinidad. Horizontes Antropológicos. Porto Alegre, v. 10, n.21

O GLOBO. (2020). PM descumpre decisão do STF e geram tiroteio na Maré, agentes negam ação. $\mathrm{O}$ Globo, Rio de Janeiro, 17 jun. Disponível em: 
https://ultimosegundo.ig.com.br/policia /2020-06-17/ pm-descumpre-decisao-do-stfe-geram-tiroteio-na-mare-agentes-negam-acao.html. Acesso em: 14 set. 2020.

PEIRANO, Mariza. (2014). Etnografia não é método. Horizontes Antropológicos, Porto Alegre, ano 20, n. 42, p.377-391.

PREFEITURA DO RIO DE JANEIRO. (2009). Internet Itinerante é inaugurado hoje na comunidade da Maré. Rio de Janeiro, 17 dez. <http://www0.rio.rj.gov.br/pcrj/ destaques/ciencia_tecnologia_internet_intinerante_mare.htm $>$ Acesso em: 13.set. 2020.

QUIJANO, Aníbal. (1998). Colonialidad del poder, cultura y conocimiento en América Latina. Ecuador Debate, Quito, n. 44, p.227-238.

REDES DE DESENVOLVIMENTO DA MARÉ; OBSERVATÓRIO DE FAVELAS. (2012). Guia de ruas Maré. Rio de Janeiro: Mórula.

REDES DE DESENVOLVIMENTO DA MARÉ. (2019). Censo populacional da Maré. Rio de Janeiro: Mórula.

RIANELLI, Erick; FREIRE, Felipe; SANTOS, Guilherme; LEITÃO, Leslie. (2020). Complexo da Maré concentra mais de 240 foragidos da Justiça; moradores vivem acuados. G1, Rio de Janeiro, 26 ago. Disponível em: <https://g1.globo.com/rj/rio-dejaneiro/noticia/2020/08/26/bunker-de-bandidos-complexo-da-mare-tem-244foragidos-da-justica.ghtml>. Acesso em: 26 ago. 2020.

RIO DE JANEIRO. (1988). Decreto 7980 de 12 de agosto de 1988. Rio de Janeiro: Prefeitura.

RODRIGUES, Theófilo; FERREIRA, Daniel. (2020). Estratégias digitais dos populismos de esquerda e de direita: Brasil e Espanha em perspectiva comparada. 2020. Trabalhos em Linguística Aplicada. Campinas, v. 59, n.2, p.1070-1086.

SEGATA, Jean. (2016). Dos cibernautas às redes. In: SEGATA, Jean; RIFIOTIS, Teophilos. (Orgs.). Políticas etnográficas no campo da cibercultura. Brasília: ABA Publicações; Joinville: Letra D'água, p.91-114.

SILVA DE LIMA, Alberto Jorge; CUKIERMAN, Henrique Luiz. (2011). Da integração das Américas a um cemitério de pipas: a construção de um projeto de inclusão digital na Favela da Maré. Revista Iberoamericana de Ciencia, Tecnología y sociedad, Ciudad Autónoma de Buenos Aires, v. 6, n. 18, p.183-197.

SILVA, Daniel N. (2020). The pragmatics of chaos: parsing Bolsonaro's undemocratic language. Trabalhos em Linguística Aplicada, Campinas, v.59, n.1, p.507-537.

SILVA, Daniel do Nascimento e; LOPES, Adriana Carvalho. (2019). "Yo hablo un perfeito portuñol”: Indexicalidade, ideologia linguística e desafios da fronteira a políticas linguísticas uniformizadoras. Revista da ABRALIN, v. 17, n. 2, 27.

SIMMEL, Georg. (1983). Sociologia. São Paulo: Ática. 
CABANZO; RODRÍGUES | Apuntes etnográficos sobre lo digital y la lengua en Maré | 18

Es antropóloga y traductora. Posee doctorado en Antropología - Universidade Federal Fluminense, maestría en Comunicação e Cultura - Universidade Federal do Rio de Janeiro e bacharelado en Antropología - Universidad Nacional de Colombia.

\section{Danielly Rodrigues}

Es ilustradora gráfica y profesora particular de español. Nació y vive en la favela de Maré, Río de Janeiro, Brasil.

Fecha de recepción 30/09/2020

Fecha de aceptación 04/12/2020 